\title{
A short impression of the exhibition of the ALA Midwinter Meeting 2008, which was held 11-15 January 2008 in Philadelphia, PA, USA
}

The exhibition this year may be characterized as follows:

- a smaller number of exhibitors than in other years (more than 500 exhibitors),

- a lack of new and major product innovations,

- more - interesting - Open Source Software (OSS) products,

- consolidation in general, notably in the software area,

- more outsourcing offerings, also via SaaS (Software as a Service),

- the introduction of WorldCat Local,

- concentration by ILS vendors on search/discovery/delivery products, like Innovative's ENCORE, PRIMO $^{1}$ (Ex Libris), INDIGO (TLC), ARENA (Axiell) and PRESTO (InMagic) - the last two companies have not been exhibitors (for the sake of completeness only) and

- more 3rd party products by niche companies, who have no an underlying ILS product, as well as by ILS vendors.

WorldCat Local may give libraries a presence on the Internet, as one library alone is nothing on the Internet, but together libraries may create a very robust presence in accordance with the long tail principle.

\section{The long tail principle and its application}

Libraries have to become aware of the long tail principle (and of course apply it), which is partly responsible for the success of Amazon. The "long tail" principle has been introduced by Anderson ${ }^{2}$ and the theme has been picked-up by Lorcan Dempsey, Chief Strategist of OCLC. ${ }^{3}$ In the library context it means:

- the aggregation of dispersed library materials and web-based materials, incl. library catalogues (aggregation of the offers);

\footnotetext{
${ }^{1}$ The PRIMO application will provide a one-stop shop offering access to all of the Library's collections and enables a library to improve access to all its print, electronic, audio and video resources by reintegrating these increasingly fragmented collections into a Web 2.0 environment that will engage our users.

${ }^{2}$ Chris Anderson: The Long Tail. Wired Magazine, No. 12, 10 October 2004.

${ }^{3}$ Lorcan Dempsey: Libraries and the long tail - some thoughts about libraries in a network age. D-Lib Magazine, April 2006 (www.dlib.org./slib/april06/dempsey/04dempsey.html).
} 
- the aggregation of the demand site by knowing everything about the user in a meaningful way profiling (aggregation of demand);

- matching the aggregated offers and demands, which means that special products or less-frequently used/requested materials will find a customer (who is/may be willing to pay).

It would mean that all libraries in a country/region would together have the usage they need to survive and to offer users the "Google/Amazon/AbeBooks" experience. "Libraries could connect their individual collections into a vast super-collection that can go further down the tail than any single institution could afford". 4

In the literature ${ }^{5}$ we find a large amount of examples for a power-law distribution of tags (and other information units) with its typical "long tail". However, that is not the only "typical" distribution. Another kind, called "inverse logistic", consists of a long tail as well, but there are some tags on the left-hand side of the distribution (the "long trunk") with (more or less) the same high values. Both distributions offer the possibility to create a new retrieval tool: in an inverse logistic distribution, all tags of the long trunk, and in a power-law distribution ("power tags"). This could be a feasible way to overcome the information overload in formal science communication. The 'long tail' and the 'long trunk' are closely related to the in the library circles well-known $80-20 \%$ distribution, based on the Gauss curve.

\section{LITA/Brett Butler Entrepreneurship Award winner announced}

CHICAGO - Glenn Peterson is the 2008 recipient of the LITA/Brett Butler Entrepreneurship Award for his development of EngagedPatrons.org. Engagedpatrons.org provides low-cost and free Web site services for public libraries. The site went live in May 2006, enabling even small- and medium-sized libraries the ability to offer high-quality Web services to their patrons, services that most would otherwise be unable to provide.

EP focuses on services that engage the library's patrons: interactive services that allow patrons to participate on their library's Web site. These services require computer programming expertise, often lacking within libraries and very expensive to hire on a contract basis. Drawing on more than 10 years experience developing Web sites for Hennepin County (Minn.) Library, founder Glenn Peterson created a series of "plug-and-play" Web services that libraries can integrate into their existing Web presence.

These services include:

- Library events listings, including patron-initiated online registration;

- Blogs, including patron comment capabilities;

- Contact forms for soliciting patron feedback;

- RSS feeds for events, blogs or other custom feeds;

- Custom database applications for libraries wishing to make local databases Web-accessible.

EP hosts the services on its own Web servers; member libraries do not need to install any software or hardware. No programming is required; library staff use Web-based forms to enter the library's information, and EP's scripts do the rest.

\footnotetext{
${ }^{4}$ www.thelongtail.com/the_long_tail/2005/09//long_tail_101.html.

${ }^{5}$ W.G. Stock, On relevance distributions, Journal of the American Society for Information Science and Technology 57(8) (2006), 1126-1129.
} 
EP works with individual libraries to customize EP services to blend into the look and feel of each library's Web site enabling the library's patrons to move seamlessly between EP-hosted services and the library's own web pages.

Services are free to libraries receiving less than $\$ 1$ million per year in total income. For larger libraries, affordable annual fees apply to events listings and blogs, while other services are free to all.

In the first 18 months of operation, more than 200 libraries have become members; 39 states are represented, as well as Canada and New Zealand.

"EngagedPatrons.org is a labor of love, as well as being an innovative service to offer which enhances the delivery of library resources to end users", said Nancy Colyar, chair of the award committee. "The committee selected Mr. Peterson for the 2008 award for the widespread effect of this technology, made available to a community that would never have the ability to provide Web services on their own".

The LITA/Brett Butler Entrepreneurship Award recognizes exemplary entrepreneurship by providing an innovative product or service designed to meet the needs of the library world. Sponsored by Gale ${ }^{\circledR}$, a part of Cengage Learning, and the Library and Information Technology Association (LITA), a division of the American Library Association (ALA), the award includes a check for $\$ 5,000$ and a certificate of recognition. The award will be presented at the LITA President's Program on Sunday, June 28, 2008, at the ALA Annual Conference in Anaheim, CA.

Library and Information Technology Association (LITA) members are information technology professionals dedicated to educating, serving and reaching out to the entire library and information community.

Contact:

Mary Taylor

LITA

Tel.: +(312) 2804267

E-mail: bmtaylor@ala.org 